\title{
An alternative approach to influencing behaviour: Adapting Darnton's Nine Principles framework for scaling up individual upcycling
}

\author{
Kyungeun Sung ${ }^{a *}$, Tim Cooper $^{\mathrm{a}}$, Sarah Kettley ${ }^{\mathrm{a}}$ \\ ${ }^{a}$ Nottingham Trent University \\ *Corresponding author e-mail: kyungeun.sung2013@my.ntu.ac.uk
}

\begin{abstract}
Behaviour change or influencing behaviour has recently been recognised as a new role of design by design academics and practitioners. Some approaches have been explored in past research, yet most focused on behaviour intervention generation as a form of product design or communication design. In the meantime, increasing interest in design as a way of thinking and as an effective tool for policy and service innovation in the public sector calls for wide-ranging approaches for design and policy interventions. This paper therefore suggests an alternative approach as a response to such calls. Darnton's Nine Principles framework is critically reviewed as an overarching framework, and adapting this framework, the early stages of behaviour intervention are proposed. The application of the alternative approach to influencing behaviour is demonstrated by giving an example of scaling up individual upcycling. The paper concludes by discussing the value and usefulness of the suggested approach.
\end{abstract}

Keywords: Darnton's Nine Principles framework; design for behaviour change; upcycling; sustainable design

\section{Introduction}

Design academics and practitioners have recently recognised the role of design in influencing human behaviour for desirable outcomes (e.g. environmentally or socially beneficial) instead of, or in addition to, fulfilling the needs and wishes of consumers (Brown \& Wyatt, 2010; Clune, 2010; Lilley, 2007; Lockton, Harrison, \& Stanton, 2009; Niedderer, 2013). This recently recognised new role and practice of design, design for behaviour change, has so far been applied to a number of areas such as sustainability, crime prevention, health enhancement and safety (Niedderer, 2013). In these areas of application, a range of approaches to influencing behaviour - either changing undesirable behaviour or reinforcing desirable behaviour - by design have been explored. For example, Lilley (2007)

This work is licensed under a Creative Commons Attribution-NonCommercial 4.0 International License. 
investigated the feasibility of applying design-led approaches to influence user behaviour to reduce the negative social impacts of products during use and proposed a framework of attributes for behaviour changing devices. Tang (2010) proposed a Design Behaviour Intervention Model to bridge the social-psychological theories of behaviour and the behaviour intervention approaches based on design to influence more sustainable actions for reducing environmental household impacts. Clune (2010) applied the four stages from Community Based Social Marketing (McKenzie-Mohr \& Smith, 1999) for design interventions for behaviour change. Lockton et al. (2010) presented the Design with Intent Method, an innovation tool for designers working in product and system design to influence user behaviour for improving performance and reducing user error. Dorrestijn (2012) proposed The Product Impact Model for product development professionals, reflecting different modes of interaction - physical, cognitive, environment and abstract. Niedderer (2013) suggested the use of attitude change as a basis for lasting behaviour change, namely Mindful Design - using mindfulness (Langer, 1989) as an opened attitude leading to increased awareness, reflection and responsibility in design.

Most of these approaches have focused on products or communication information and graphics as a form of intervention. Investigation into interventions beyond product and communication design (e.g. service design) appear to be relatively lacking. In the meantime, the increasing interest in design as a way of thinking and as an effective tool for policy and service innovation in the public sector (Bason, 2014; 2010; Boyer, Cook, \& Steinberg, 2011; European Commission, 2012), calls for more general or wide-ranging approaches to design and policy interventions.

The aims of the paper, therefore, are threefold. The first is to critically review Darnton's Nine Principles framework (Darnton, 2008a) as an overarching framework that addresses the need for design and policy intervention. The second is to show how the framework could be adapted especially for the situation where the behaviour under investigation has been relatively unexplored and there are insufficient resources to engage in prototyping and piloting the interventions before making a critical decision to commit substantial amount of resources. The third is to demonstrate an application of the adapted framework through the case of scaling up individual upcycling.

\section{Darnton's Nine Principles framework for behaviour intervention}

Amongst psychologist and policy makers it is a common knowledge that behaviour understanding and behaviour change policies rest on certain behavioural models (either explicitly or implicitly) - exhibiting, for example, what the behaviour is, what its antecedents are, and how it is influenced, shaped and constrained. Darnton's Nine Principles framework was designed to "integrate [such] behaviour models with theoretical understanding of effective approaches to change. The framework provides a starting point for selecting [appropriate] models and developing behaviour change interventions." (Darnton, 2008a, p. 23). It is based on theory-based guidance for planning interventions, such as Community 
Based Social Marketing (McKenzie-Mohr \& Smith, 1999) and Stern's Principles (Stern, 2000), yet it puts the building of behavioural models into the heart of the intervention developing process (Darnton, 2008a).

Darnton suggests the Nine Principles as: (1) identify the audience groups (or actors) and the target behaviour; (2) identify relevant behavioural models and draw up a shortlist of influencing factors; (3) select the key influencing factors to design objectives in a draft strategy for the intervention; (4) identify effective intervention techniques; (5) engage the target audience for the intervention; (6) develop a prototype intervention; (7) pilot the intervention and monitor continuously; (8) evaluate impacts and processes; and (9) feedback learning from the evaluation (Darnton, 2008a). See Figure 1 for a framework based on these nine principles.

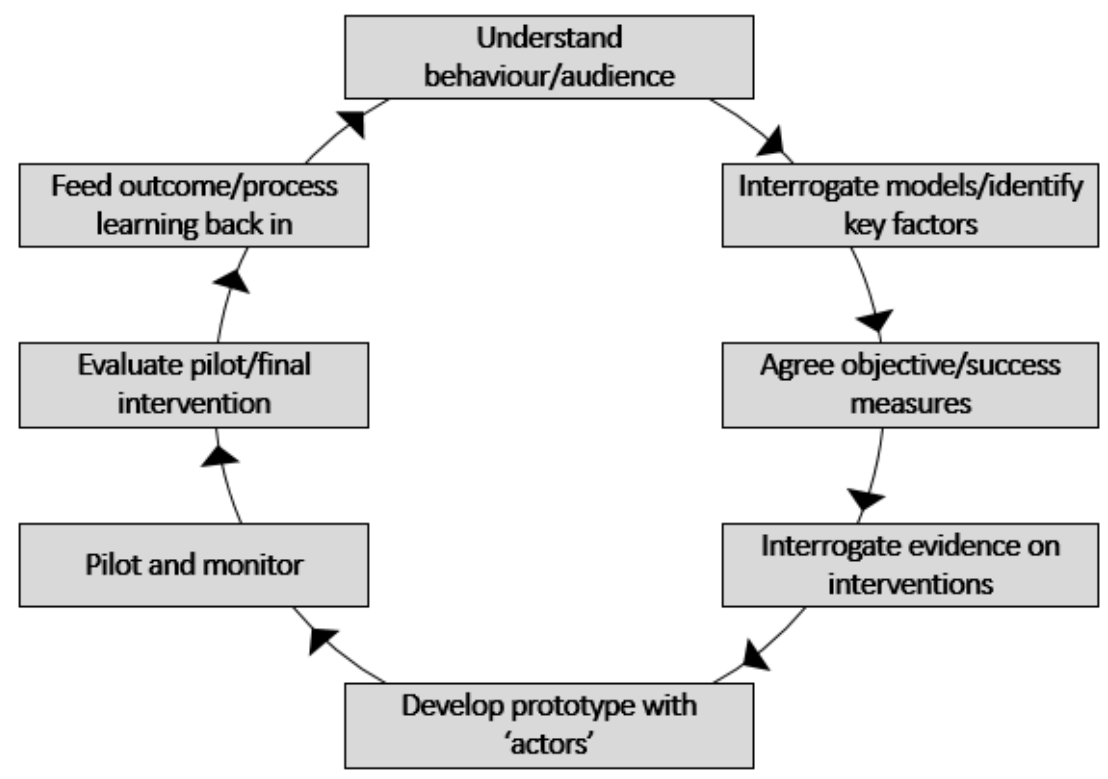

Figure 1 The Nine Principles framework from Darnton (2008a). Darnton suggested nine principles yet provided eight stages in the framework by combining principle (5) and (6) for the stage five, develop prototype with 'actors'.

Darnton seemed to have assumed that identifying target behaviour and actors suffices to understand behaviour/audience; that extracting key influencing factors from the models and past empirical research result is valid and appropriate in all cases; and that co-creating the intervention prototype with actors is prerequisite for finding out effective interventions. But what if the behaviour under investigation has not yet been explored before such that it is evident that empirical research is required in the new situation? And what if there are not enough resources (e.g. time, financial support) to proceed with prototyping with actors and piloting before making a critical decision of committing significant amount of resources? Adaptations of the Darnton's framework were made to address these issues. 


\section{Setting the scene: The case of scaling-up individual upcycling}

This section describes the case of scaling up individual upcycling, which will be used to illustrate how Darnton's framework could be adapted and applied to behaviour change intervention.

\subsection{Project background}

The UK is legally obliged to reduce its greenhouse gas emissions by at least $80 \%$ by 2050 . As part of the Government's commitment to achieving this reduction, the Research Councils UK Energy Programme established six End Use Energy Demand Centres (EUED, 2015). The Centre for Industrial Energy, Materials and Products (CIE-MAP) is one of these six centres and focuses on materials and embodied energy reduction in the UK and beyond. ${ }^{1}$ The first author's PhD research as part of CIE-MAP explores the emerging household behaviour of individual upcycling in the UK as an important opportunity at the domestic level (and potentially beyond) for contributing to sustainable production and consumption by reducing carbon emissions related to materials and energy.

\subsection{Individual upcycling as environmentally significant behaviour}

Environmentally significant behaviour is, according to Stern, behaviour that "changes the availability of materials or energy from the environment, or alters the structure and dynamics of ecosystems or the biosphere itself." (Stern, 2000, p. 408). It is often used interchangeably with pro-environmental behaviour, green consumer behaviour, environmentally responsible behaviour, environmentally friendly behaviour, ecological behaviour, sustainable behaviour, sustainable lifestyle, etc. Despite differences in terminology, the common denominator is the idea that individual behaviour can collectively impact positively on the environment.

Individual upcycling, the creation or modification of any product from used products, components or materials in an attempt to generate a product of higher quality or value than the compositional elements (Sung, Cooper, \& Kettley, 2014) by individuals, is another example of environmentally significant behaviour. ${ }^{2}$ It may be assumed to be a more sustainable way of making, crafting or personalising products for individuals than doing so with virgin materials only. When scaled up to a meaningful level with appropriate interventions, it could, in theory, significantly reduce the need for new products as well as

\footnotetext{
1 RCUK Centre for Energy Epidemiology (UCL-Energy) has focused on an energy epidemiological approach that looks to reinterpret the health sciences research structure; The Centre on Innovation and Energy Demand on developing a socio-technical understanding of the emergence, diffusion and impact of low energy innovations; DEMAND (Dynamics of Energy, Mobility and Demand) Centre on tackling the fundamental question of what energy is for; i-STUTE (The interdisciplinary centre for Storage, Transformation and Upgrading of Thermal Energy) on examining the potential for energy use reduction in heating and cooling (EUED, 2015).

2 The term, upcycling, was recently coined and can be traced back to the interview with Riner Pilz (Kay, 1994). Pilz, in the context of architecture and interior design, said, "Recycling, I call it down-cycling. They smash bricks, they smash everything. What we need is upcycling, where old products are given more value, not less." (Kay, 1994, p.14). The more widely understood meaning of upcycling in academia, however, comes from Braungart and McDonough (2002). They see upcycling as the process that maintains or upgrades materials' value and or quality in their second life and beyond in a closed-loop industrial cycle. This paper uses the definition from Pilz and adds 'individual' in front of 'upcycling' in order to reflect the emerging, contemporary individual activities of upcycling as well as to distinguish it from 'industrial upcycling' which more often refers to improved recycling rather than product recreation.
} 
municipal solid waste. Reduced need for new products would lessen the amount of materials and industrial energy used in production with new materials, and therefore contribute to reductions in greenhouse gas emissions (Ali, Khairuddin, \& Abidin, 2013; Goldsmith, 2009; Szaky, 2014). In addition, the decreased amount of municipal solid waste may obviate the need for additional landfill spaces. The benefit of individual upcycling is not only limited to positive environmental benefits. Individual upcycling can save money for individuals - fulfilling needs with fewer financial resources (Frank, 2013; Lang, 2013) - and, in theory, lead to new jobs in small- or medium-sized enterprises (Sung \& Cooper, 2015). It can, furthermore, provide participants with sociocultural and psychological benefits such as learning and empowering, a sense of community, relaxing (Sung, Cooper, \& Kettley, 2014).

\subsection{Scaling-up of individual upcycling by behaviour interventions}

Evidence suggests that the overall number of people who upcycle items has recently increased in developed countries, including the UK, possibly as a response to the contemporary Maker ${ }^{3}$ Movement (Anderson, 2012; Lang, 2013), physical resources (e.g. Maker Faire, Hackspace/Makerspace) and digital resources (e.g. Instructables, Etsy). Despite this growing interest, individual upcycling is evidently still a marginal activity. Considering the potential benefits of individual upcycling environmentally, as well as economically and socio-culturally, one of the pertinent questions from the perspective of sustainable design concerns scaling up (Ceschin, 2012; van den Bosch, 2010). How can this emerging, yet still marginal activity, be scaled up into a mainstream everyday activity in households (and possibly also in industries) to make a bigger impact on the environment and society? One solution to create a meaningful level of scaling up would be to generate effective intervention strategies for influencing consumer behaviour.

\section{Adapted framework and its application to individual upcycling}

This section illustrates an adapted framework from Darnton's Nine Principles framework (Darnton, 2008a), focusing on the early stage activities in the behaviour intervention (i.e. behaviour research and intervention strategies generation). The adaptation in these early stages was made to understand relatively unexplored behaviour for extracting valid key influencing factors based on empirical results, and to design effective interventions with limited resources without having to fully engage in co-development of prototype with actors and piloting. The adapted model does not suggest that later stages of prototyping and piloting are unnecessary. Rather, it suggests how the cycle can be split up between researchled intervention generation process and the rest of them for the half-way decision-making and planning in order to effectively invest resources in prototyping and piloting of the prioritised intervention options.

\footnotetext{
3 The term, 'Maker', could apply to potentially everyone in the sense that "we are all makers. We are born makers: just watch a child's fascination with blocks, Lego, etc. It's not just about workshops, garages and man caves. If you love to cook, you are a kitchen Maker and your stove is your workbench. If you love to plant, you are a garden Maker. Knitting and sewing, scrap-booking, beading, and cross-stitching - all Making." (Anderson, 2012, p. 13).
} 
The premise in this approach is that the design researcher or practitioner has already identified which specific behaviour to target. There are three stages in the early stages of this adapted framework. Each consists of two steps. The first includes identifying behaviour model and understanding behaviour and consumers. The second includes refining the behaviour model for operationalisation and identifying key drivers, facilitators and barriers. The third includes designing effective intervention strategies and, evaluating and improving the draft strategies (Figure 2). The following sub-sections elaborate each stage and demonstrate an application of the approach through the example of scaling up individual upcycling. This project is ongoing and currently at the second step in stage three - evaluate and improve the draft strategies.

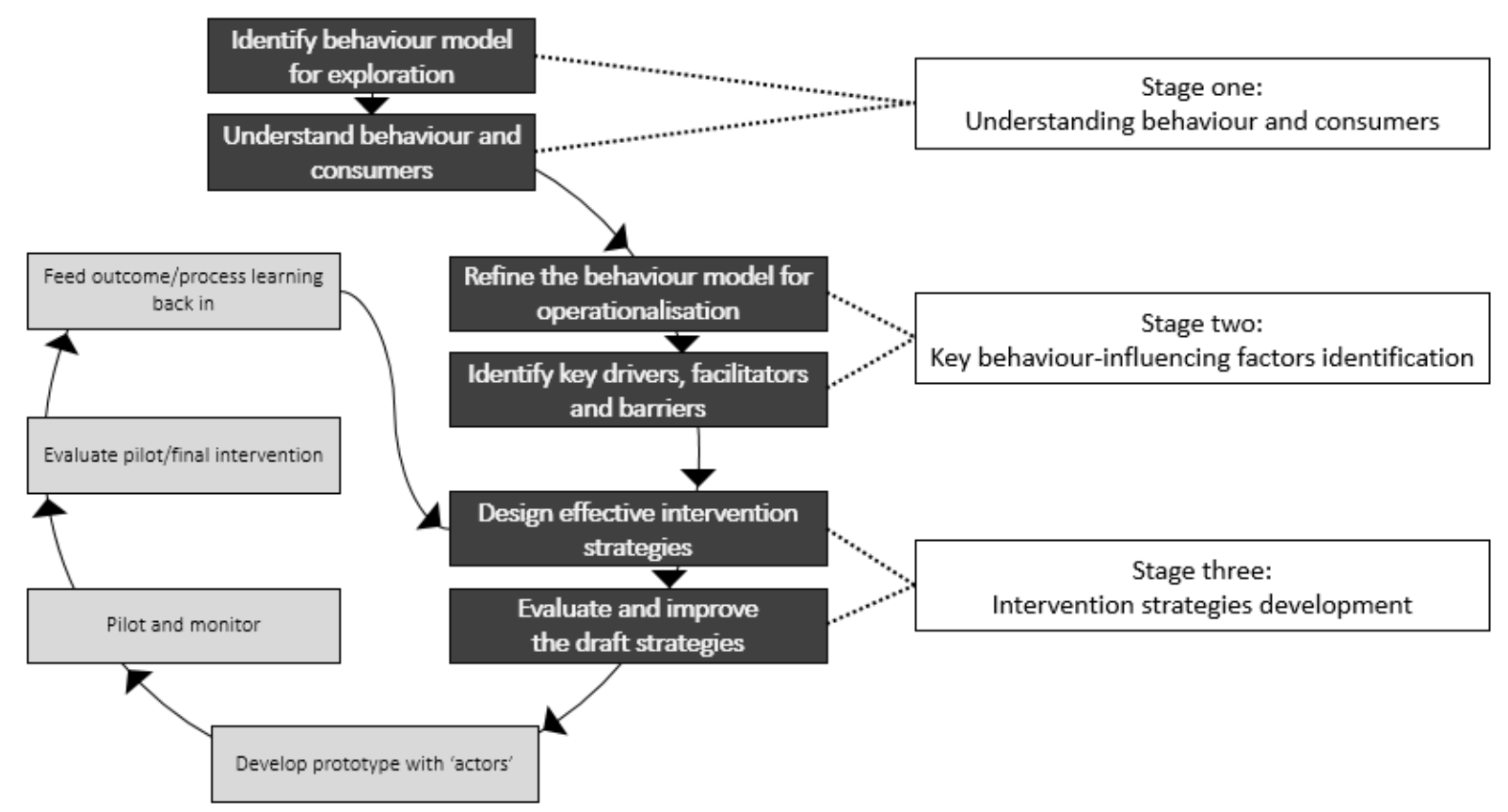

Figure 2 Adapted framework based on the Darnton's Nine Principles framework (Darnton, 2008a). Dark grey boxes represent research-led intervention generation process where the adaptations were made, and light grey boxes are part of Darnton's original framework

\subsection{Stage one: Understanding behaviour and consumers Step one: Identify behaviour model for exploration}

Identifying a suitable model for the targeted behaviour by literature review is a crucial first step in a sense that "different behaviours are driven by different factors and in different combinations" (Darnton, 2008a, p. 25). In addition, the model used determines the scope of the understanding in terms of the number of behaviour-influencing factors. ${ }^{4}$ As a designer

\footnotetext{
4 For example, Schwartz' Norm Activation Theory (Schwartz, 1968; Schwartz \& Fleishman, 1978) is more suitable for moral or ethical behaviour, and it is a more parsimonious model with only three factors of behaviour (i.e. awareness of consequences, ascription of responsibility, and personal norm). On the other hand, Bagozzi's Comprehensive Model of Consumer Action (Bagozzi \& Warshaw, 1990; Perugini \& Bagozzi, 2001) is more suitable for complex and multifaceted behaviour such as consumption, and it provides more than 20 behaviour-influencing factors (e.g. goal feasibility, anticipated positive emotions, outcome expectancies, attitudes, subjective norms, situational forces, etc.).
} 
without any psychology or sociology educational background, choosing the right model for the targeted behaviour might be a daunting task for some, in which case, Darnton's 'practical guide' to models (Darnton, 2008a) could be of help. This provides a table that matches behaviours to models in eight different behaviour domains (i.e. community participation, consumption, environment, health, transport, work \& savings, addictive and other)..$^{5}$

In the case of scaling up upcycling, a thorough literature review was conducted; this confirmed that behaviour is complex and therefore should be understood by both internal (e.g. attitude, social factors, emotions, habits) and external (e.g. situational constraints and conditions) factors (Egmond \& Bruel, 2007; Jackson, 2005a; Kallbekken, Rise, \& Westskog, 2008; Martiskainen, 2007). Most notably, Jackson's extensive review of behaviour in the context of sustainable consumption concluded that "[a] grand unified theory of human behaviour is probably impossible. But a pragmatic synthesis is a useful starting point for policy design. Triandis' early theory of interpersonal behaviour provides a good illustration of such a synthesis." (Jackson, 2005b, p. 5). Similarly, Martiskainen (2007) reviewed different models of behaviour and change regarding households' energy-related behaviour and recommended Triandis' model for its comprehensiveness and inclusion of habits. A number of integrative or comprehensive models, such as Integrative Agent-Centred Framework (Feola \& Binder, 2010), Comprehensive Action Determination Model (Klöckner \& Blöbaum, 2010) and the combination model of Theory of Planned Behaviour and the Value-BeliefNorm Theory (Kallbekken, Rise, \& Westskog, 2008), showed that most elements in these models are part of Triandis' model. Furthermore, Triandis' model is known for its wider applicability unlike other models: for instance, Norm Activation Theory is more appropriate for predicting altruistic behaviour and Health Belief Model for preventative health behaviour (Darnton, 2008b). It has been used for technology adoption behaviour (Gagnon, Sanchez, \& Pons, 2006), civic behaviour (Cotterill, Richardson, Stoker, \& Wales, 2008), dietary behaviour (Salonen \& Helne, 2012) and behaviour intervention model in product design (Tang, 2010) in addition to sustainable consumption, pro-environmental behaviour or energy-related behaviour.

Individual upcycling may be assumed to be a form of sustainable production and consumption, not necessarily with pure pro-environmental intention. Some consumers may see it as environmentally significant behaviour, while for others it may be a way of engaging with their community, or about product personalisation. Individual upcycling, therefore, needs a versatile model which can not only explain environmentally significant behaviour but also other behaviour domains (e.g. community participation, 'craft consumption' ${ }^{6}$ ). Therefore, Triandis' Theory of Interpersonal Behaviour (Triandis, 1977), from its

\footnotetext{
5 The examples are such as Theory of Reasoned Action for voter choice, Bagozzi's Theory of Trying for shopping, Stern's ABC model for recycling, Theory of Planned Behaviour for taking exercise, etc.

6 Craft consumption is "the consumption activity in which the product concerned is essentially both made and designed by the same person and to which the consumer typically brings skill, knowledge, judgement and passion while being motivated by a desire for self-expression" (Campbell, 2005, p. 1).
} 
comprehensive nature and wider applicability, was considered to be the most suitable model to understand individual upcycling behaviour.

\section{Step two: Understand behaviour and consumers}

Understanding behaviour and consumers could be more exploratory for designers unlike Darnton's original approach which only includes identifying which actors and which specific behaviour to target (Darnton, 2008a). Designers could investigate each behaviour factor and consumer profiles in a qualitative way, using interviews, focus groups, etc.

In the case of individual upcycling, semi-structured interviews ${ }^{7}$ were conducted with 23 UKbased consumers. The interview schedule was designed on the basis of behaviourinfluencing factors in Triandis' Theory of Interpersonal Behaviour: perceived benefits, norms, roles, self-concept, emotions, habits, and facilitating conditions ${ }^{8}$. The questions were such as "What benefits do you expect and see from upcycling?" or "What conditions do you think have facilitated your upcycling so far?" The results provided a variety of elements (e.g. which perceived consequences) in each behaviour factor of individual upcycling (which can then be used for the quantitative study in the next stage). Several insights into the potential differences arising from demographic characteristics were found: for instance, women appeared to view their relationship roles more relevant to upcycling whereas men viewed occupational roles more relevant.

\subsection{Stage two: Key behaviour-influencing factors identification Step one: Refine the behaviour model for operationalisation}

This is the step in which one can make sure that the selected model is operationalisable for quantitative research (i.e. usable for survey). The activity can be either refining the behaviour model or identifying the existing model as tested research instrument by further literature review.

In the case of scaling up upcycling, some issues of Triandis' model were identified through further investigation. There is no clear guidelines for the operational definition of the variables in the original Triandis' model (Araujo-Soares \& Presseau, 2008), and a few adapted models from Triandis' original model did not show the agreed approach to measure each variable (Gagnon, et al., 2003; Bamberg \& Schmidt, 2003; Knoeri \& Russell, 2014). In order to address such issues, Triandis' Theory of Interpersonal Behaviour model was combined with another model, the Theory of Planned Behaviour (Ajzen I. , 1991; Ajzen \&

\footnotetext{
7 The method was chosen for its flexibility which allows for probing when necessary, while keeping the pre-determined interview schedule (Barriball \& While, 1994).

8 Perceived benefits mean 'perceived consequences with positive value attached to the expected and/or experienced consequences'. Norms are "beliefs that certain behaviours are correct, appropriate, or desirable" and roles are "sets of behaviours that are considered appropriate for persons holding particular positions (e.g. father, leader, salesperson) in a group" (Triandis, 1977, p. 8). Self-concept refers to "a person's ideas about who he or she is" (p.9). Emotions (or affect) are what a person feels at the thought of the behaviour - positive or negative and strong or weak (Triandis, 1977). The habit to act is "measured by the number of times the act has already been performed by the person" (p.10). Facilitating conditions are "the total situation in which a subject and another find themselves" (p.208).
} 
Fishbein, 1980), one of the most widely used models in behaviour research, for the improved operationalisability.

\section{Step two: Identify key drivers, facilitators and barriers}

Key drivers and facilitators for and barriers to the targeted behaviour can be identified through quantitative research (e.g. survey) based on the selected behaviour model, using the variables identified from the previous qualitative understanding research. For the statistical analysis to identify key influencing factors, multiple regression analysis (Cohen, Cohen, West, \& Aiken, 2013), for example, can be used to reveal how much of the behaviour variance is explained by the model and which factors are more influential.

In the case of individual upcycling, an online survey ${ }^{9}$ was used. The population of interest (or behaviour actors) was Makers, defined by Anderson (2012) to include makers, hackers, crafters, tinkerers, fixers, knitters, gardeners, etc. (potentially everyone; see footnote 1). The survey was administered through websites which the interview participants mentioned as the most frequently and regularly visited by themselves. 122 responses were attained from British residents. The analysis results revealed that intention ${ }^{10}$ explains the largest variance in behaviour frequency, and that attitude, ${ }^{11}$ personal norm ${ }^{12}$ and perceived behaviour control ${ }^{13}$ showed stronger unique contribution in explaining the variance in intention. The implication of the results is that to be effective, intervention strategies should prioritise building positive attitude towards individual upcycling, establishing positive personal norm about it, and developing competent perceived control over upcycling in order to increase intention, leading to more widely practiced and frequent upcycling (i.e. scaling up of individual upcycling).

\subsection{Stage three: Intervention strategies development \\ Step one: Design effective intervention strategies}

Designing effective intervention strategies is based on the key behaviour-influencing factors identified from the previous stage. This first step requires benchmarking of existing intervention strategies. Darnton (2008a) suggests that Abraham and Michie's work in developing a typology of behaviour change techniques through a meta-analysis (Abraham \& Michie, 2008) is a useful starting point. Another useful source might be Defra's 4E approach (Defra, 2005) - Enable, Engage, Encourage and Exemplify - particularly when one deals with

9 Online survey was chosen for its ability to reach large number of people within a relatively short time with relatively inexpensive cost (Fink, 2013).

10 Intention is the immediate antecedent and key determinant of behaviour in many popular behaviour models such as the Theory of Reasoned Action (Fishbein \& Ajzen, 1975) and the Theory of Planned Behaviour (Ajzen \& Madden, 1986) as well as the Theory of Interpersonal Behaviour (Triandis, 1977). The typical intention questions are, for example, "If I have the opportunity, I will ..." or "I intend to ..."

11 Attitude toward a behaviour is "a person's overall evaluation of performing the behaviour in question" (Ajzen I. , 2002, p. 5). The typical attitude questions are such as "For me, ... is pleasant/good/worthwhile/enjoyable/etc."

12 Personal norm is "the feeling of personal obligation regarding the performance of a given behaviour (Gagnon, Sanchez, \& Pons, 2006, p. $3)$.

13 Perceived behaviour control refers to "control over performing the defined behaviour" (Ajzen I. , 2002, p. 2). It is the respondents' perception on their ability to perform the behaviour. The typical questions are such as "For me, ... would be possible." or "It is mostly up to me whether or not I ..." 
behaviour related to sustainable development. Designers in this step, taking into account the key behaviour factors and existing intervention strategies, are expected to use 'strategic design" - "a design activity aiming at an integrated system of products, services and communication, based on new forms of organisation, based on the roles reconfiguration [...]; a design developing strategy linking long term goals with existing trends" (Manzini \& Vezzoli, 2003, p. 856) - for their ideation.

In the case of scaling up upcycling, the initial intervention ideas were generated on the basis of the identified, key behaviour factors - intention, attitude, personal norm and perceived behaviour control. These initial ideas were then mapped onto the table of Defra's $4 \mathrm{E}$ actions, and extra ideas added to the table.

\section{Step two: Evaluate and improve the draft strategies}

Evaluating and improving the draft strategies/ideas is an important final step before developing any prototype with actors (or the targeted population for intervention). In this step, the draft strategies on policy and design intervention can be explored and evaluated, preferably by a group of experts. The evaluation criteria may include desirability, importance (in terms of potential impact on scaling up) and feasibility (technical, economic, and political). New suggestions can be made. Taking into account the agreed evaluation results as well as new suggestions and comments, the draft strategies can be improved for prototyping and piloting.

In the case of scaling-up upcycling, a semi-Delphi method ${ }^{14}$ is to be used. The expertise will include psychology, policy studies, sociology, innovation studies and design. The invited experts will be asked, through an online questionnaire, to review all interventions for scaling up individual upcycling in the UK, make comments, rate the level of importance and feasibility of each intervention, vote for the most suitable actor for each intervention, suggest new interventions if any, and select the five most important interventions. A subsequent focus group with the same expert group will facilitate the in-depth conversation about possible disagreements amongst experts in different disciplines. It is hoped that by the end, there would be a list of effective and feasible intervention strategies.

\section{Conclusion}

The paper critically reviewed Darnton's Nine Principles framework as an overarching framework that addresses the need for design and policy intervention. Some limitations were identified and adaptations were made accordingly. Adapting the framework, the paper elaborated the early stages of behaviour intervention process - from understanding behaviour and consumers to designing intervention strategies. The application of the

14 The Delphi method is typically used to estimate the impact and consequences of any particular option, or to examine acceptability of any given option, in order to make an informed judgement in the fields of social policy and public health under conditions of uncertainty. The method often consists of a number of questionnaire studies for exploration and evaluation (Adler \& Ziglio, 1996). It is semi-Delphi because it includes one questionnaire-based study combining exploration and evaluation, followed by FG for further discussion. 
adapted framework was demonstrated through the example of scaling up individual upcycling.

The suggested framework might be more useful for strategic design than, for instance, designing a particular product. Its applicability is not limited: it can be applied to any behaviour domain for design and policy interventions. It would be particularly useful for design researchers and practitioners in the situations where the behaviour under investigation has been understudied, and they need to go through the critical decision making process involving higher managers, clients, local authorities or funders in order to commit significant amount of resources to the next steps, prototyping and piloting. We believe that the interventions generated from this approach could be effective in terms of impact on behaviour change because the approach is based on tested behaviour models, scientific research evidence, and (potentially) experts' agreed confirmation. Or at least, this approach could provide decision makers with certain extent of guarantee that the interventions, when piloted or implemented, would create impact, and thus leading to smooth buy-in from decision makers for the next steps.

Acknowledgements: This work was funded with support from the RCUK Energy Programme's funding for the Centre for Industrial Energy, Materials and Products, grant reference EP/N022645/1, as well as a Student Research Bursary from the Design Research Society.

\section{References}

Abraham, C., \& Michie, S. (2008). A taxonomy of behaviour change techniques used in interventions. Health Psychology, 27, pp. 379-387.

Adler, M., \& Ziglio, E. (1996). Gazing into the oracle: The Delphi method and its application to social policy and public health. London: Jessica Kingsley.

Ajzen, I. (1991). The theory of planned behaviour. Organisational Behaviour and Human Decision Processes, 50, pp. 179-211.

Ajzen, I. (2002). Constructing a TPB questionnaire: Conceptual and methodological considerations. Retrieved 3 31, 2015, from http://chuang.epage.au.edu.tw/ezfiles/168/1168/attach/20/pta_41176_7688352_57138.pdf

Ajzen, I., \& Fishbein, M. (1980). Understanding attitudes and predicting social behaviour. Englewood Cliffs, NJ: Prentice-Hall Inc.

Ajzen, I., \& Madden, T. (1986). Predictions of goal-directed behaviour: Attitudes, intentions and perceived behavioural control. Journal of Experimental Social Psychology, 22, pp. 453-474.

Ali, A. S., Khairuddin, N. F., \& Abidin, S. Z. (2013). Upcycling: Re-use and recreate functional interior space using waste materials. International Conference on Engineering and Product Design, Dublin.

Anderson, C. (2012). Makers: The new industrial revolution. London: Random House Business.

Araujo-Soares, V., \& Presseau, J. (2008). Theory-based behaviour prediction and change: An interview with Gaston Godin. The European Health Psychologist, 10(September), pp. 51-58.

Bagozzi, R., \& Warshaw, P. (1990). Trying to consume. Journal of Consumer Research, 17, pp. 127140. 
Bamberg, S., \& Schmidt, P. (2003). Incentives, morality or habit? Predicting students' car use for university routes with the models of Ajzen, Schwartz, and Triandis. Environment and Behavior, 35(2), pp. 264-285.

Barriball, K. L., \& While, A. (1994). Collecting data using a semi-structured interview: A discussion paper. Journal of Advanced Nursing, 19(2), pp. 328-335.

Bason, C. (2010). Leading public sector innovation: Co-creating for a better society. Bristol: Policy Press .

Bason, C. (2014). Design for policy. Farnham: Gower.

Boyer, B., Cook, J. W., \& Steinberg, M. (2011). In Studio: Recipes for Systemic Change. Helsinki: Sitra.

Brown, T., \& Wyatt, J. (2010, July). Design thinking for social innovation. Development Outreach, pp. 29-43.

Campbell, C. (2005). The craft consumer. Journal of Consumer Culture, 5(1), pp. $23-42$.

Ceschin, F. (2012). The introduction and scaling up of sustainable product-service systems: A new role for strategic design for sustainability. Milan: Politecnico di Milano.

Clune, S. (2010). Design and behaviour change. The Journal of Design Strategies, 4(1), pp. 68-75.

Cohen, J., Cohen, P., West, S., \& Aiken, L. (2013). Applied multiple regression/correlation analysis for the behavioural science. Mahwah, New Jersey: Routledge.

Cotterill, S., Richardson, L., Stoker, G., \& Wales, C. (2008). Reinvigorating the civic: Searching for a rationale for our research programme. Southampton : Political Studies Association Conference 2008.

Darnton, A. (2008a). Practical guide: An overview of behaviour change models and their uses. London: Government Social Research Unit.

Darnton, A. (2008b). Reference Report: An overview of behaviour change models and their uses. London: Government Social Research Unit.

Defra. (2005). Changing behaviour through policy making. London: Department for Environment, Food and Rural Affairs.

Dorrestijn, S. (2012). The product impact tool: Designing for user-guiding and user-changing. Delft: Design United.

Egmond, C., \& Bruel, R. (2007). Nothing is as practical as a good theory: Analysis of theories and a tool for developing interventions to influence energy-related behaviour. Den Haag: SenterNovem.

EUED. (2015). What is EUED? Retrieved March 18, 2015, from http://www.eued.ac.uk/whatiseued

European Design Innovation Initiative. (2012). Design for growth \& prosperity: Report and recommendations of the European design leadership board. Helsinki: DG Enterprise and Industry of the European Commission. Available at: Http://ec.Europa.eu/enterprise (Accessed 4/1/13)

Feola, G., \& Binder, C. R. (2010). Towards an improved understanding of farmers' behaviour: The integrative agent-centred (IAC) framework. Ecological Economics, 69, pp. 2323-2333.

Fink, A. (2013). How to conduct surveys: A step-by-step guide (5 ed.). London: Sage.

Fishbein, M., \& Ajzen, I. (1975). Belief, atittude, intention and beahviour: An introduction to theory and research. Reading, MA: Addison-Wesley.

Frank, C. (2013). Living simple, free \& happy: How to simplify, declutter your home, reduce stress, debt \& waste. Georgetown, Ontario: Betterway Books.

Gagnon, M.-P., Godin, G., Gagne, C., Fortin, J.-P., Lamothe, L., Reinharz, D., \& Cloutier, A. (2003). An adaptation of the theory of interpersonal behaviour to the study of telemedicine adoption by physicians. International Journal of Medical Informatics, 71, pp. 103-115. 
Gagnon, M.-P., Sanchez, E., \& Pons, J. M. (2006). From recommendation to action: Psychosocial factors influencing physician intention to use Health Technology Assessment (HTA) recommendations. Implementation Science, 1(8), pp. 1-11.

Goldsmith, B. (2009). Trash or treasure? Upcycling becomes growing green trend. Retrieved 9 23, 2013, from http://www.reuters.com/article/2009/09/30/us-trends-upcycling-lifeidUSTRE58T3HX20090930

Jackson, T. (2005a). Motivating sustainable consumption. London: Sustainable Development Research Network.

Jackson, T. (2005b). SDRN briefing one: Motivating sustainable consumption. London: Sustainable Development Research Network.

Kay, T. (1994). Peiner pilz. Salvo, October, pp. 11-14.

Kallbekken, S., Rise, J., \& Westskog, H. (2008). Combining insights from economics and social psychology to explain environmentally significant consumption. Oslo: Centre for International Climate and Environmental Research.

Klöckner, C. A., \& Blöbaum, A. (2010). A comprehensive action determination model: Toward a broader understanding of ecological behaviour using the example of travel model choice. Journal of Environmental Psychology, 30, pp. 574-586.

Knoeri, C., \& Russell, S. (2014). End-users' motivations and barriers to infrastructure serviceperformance contracting: Survey procedure and design. Leeds: University of Leeds.

Lang, D. (2013). Zero to maker: Learn (just enough) to make (just about) anything (1 ed.). Sebastopol, CA: Maker Media, Inc.

Langer, E. J. (1989). Mindfulness. New York: Addison Wesley Publishing Company.

Lilley, D. (2007). Designing for behavioural change: Reducing the social impacts of product use through design. Loughborough University. Loughborough: Loughborough University .

Lockton, D., Harrison, D., \& Stanton, N. A. (2009). Choice architecture and design with intent. 9th BiAnnual International Conference on Naturalistic Decision Making, London.

Lockton, D., Harrison, D., \& Stanton, N. A. (2010). The design with intent method: A design tool for influencing user behaviour. Applied Ergonomics, 41(3), pp. 382-392.

Manzini, E., \& Vezzoli, C. (2003). A strategic design approach to develop sustainable product service systems: Examples taken from the 'environmentally friendly innovation' Italian prize. Journal of Cleaner Production, 11(8), pp. 851-857.

Martiskainen, M. (2007). Affecting consumer behaviour on energy demand. Brighton: Sussex Energy Group, Science and Technology Policy Research.

McDonough, W., \& Braungart, M. (2002). Cradle to cradle: Remaking the way we make things. London: Vintage.

McKenzie-Mohr, D., \& Smith, W. (1999). Fostering sustainable behaviour: An introduction to Community-Based Social Marketing. Gabriola Island, BC: New Society Publishers.

Niedderer, K. (2013). Mindful design as a driver for social behaviour change. IASDR Conference 2013 (p. 4561). Tokyo: IASDR.

Perugini, M., \& Bagozzi, R. P. (2001). The role of desires and anticipated emotions in goal-directed behaviours: Broadening and deepening the theory of planned behaviour. The British Journal of Social Psychology, 40, pp. 79-98.

Salonen, A. O., \& Helne, T. T. (2012). Vegetarian diets: A way towards a sustainable society. Journal of Sustainable Development, 5(6), pp. 10-24. 
Schwartz, S. (1968). Awareness of consequences and the influence of moral norms on interpersonal behaviour. Sociometry, 31, pp. 355-369.

Schwartz, S., \& Fleishman, J. (1978). Personal norms and the mediation of legitimacy effects on helping. Social Psychology, 41, pp. 306-315.

Stern, P. C. (2000). Toward a coherent theory of environmentally significant behavour. Journal of Social Issues, 56(3), pp. 407-424.

Sung, K., \& Cooper, T. (2015). Sarah Turner-Eco-artist and designer through craft-based upcycling. Craft Research, 6(1), pp. 113-122.

Sung, K., Cooper, T., \& Kettley, S. (2014). Individual upcycling practice: Exploring the possible determinants of upcycling based on a literature review. Sustainable Innovation 2014 Conference, Copenhagen, pp. 237-244.

Szaky, T. (2014). Outsmart waste: The modern idea of garbage and how to think our way out of it. San Francisco, CA: Berrett-Koehler Publisher, Inc.

Tang, T. (2010). Towards sustainable use: Design behaviour intervention to reduce household environment impact. Loughborough: Loughborough University.

Triandis, H. C. (1977). Interpersonal behaviour. Monterey, CA: Brooks/Cole Pub. Co.

van den Bosch, S. (2010). Transition experiments: Exploring societal changes towards sustainability. Rotterdam: Erasmus Universiteit Rotterdam.

About the Authors:

Kyungeun Sung is a Ph.D. candidate in the School of Architecture, Design and the Built Environment, Nottingham Trent University (NTU), UK. Her research broadly deals with sustainable design while paying close attention to sustainable production and consumption by individual upcycling.

Tim Cooper is Professor of Sustainable Design and Consumption at Nottingham Trent University and Co-Director of the Centre for Industrial Energy, Materials and Products. He specialises in product lifetimes and was Contributing Editor of Longer Lasting Products (Gower, 2010).

Sarah Kettley is Reader in Relational Design at NTU. Her research concerns with how networks of things can be designed for networks of people. She is a member of the Design for Health and Wellbeing, and the Digital Craft research groups. 